Arq. Bras. Med. Vet. Zootec., v.69, n.4, p.860-864, 2017

\title{
Dermatite piogranulomatosa ulcerativa em bovino por Corynebacterium pseudotuberculosis
}

\author{
[Ulcerative pyogranulomatous dermatitis in bovine by Corynebacterium pseudotuberculosis]

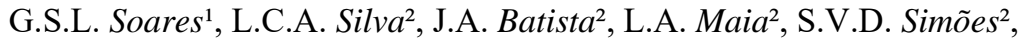 \\ E.G. Miranda Neto ${ }^{2}$ \\ ${ }^{1}$ Universidade Federal Rural de Pernambuco - Recife, PE \\ ${ }^{2}$ Universidade Federal de Campina Grande - Campina Grande, PB
}

\begin{abstract}
RESUMO
Relata-se um caso de lesão cutânea secundária à infecção por Corynebacterium pseudotuberculosis em bovino. Abscessos e múltiplas lesões cutâneas nodulares, variando de $8 \times 10$ para $20 \times 25 \mathrm{~cm}$ de diâmetro, firmes, sensíveis ao toque e sem mobilidade, algumas com superfície ulcerada, circundada por halo avermelhado e drenando secreção piossanguinolenta, e outras com superfícies alopécicas, foram identificados na região torácica lateral do animal. Exames histopatológicos e o isolamento do agente de fragmentos obtidos após remoção cirúrgica das lesões confirmaram tratar-se da forma cutânea da infecção pelo C. pseudotuberculosis. As lesões microscópicas caracterizaram-se por dermatite nodular piogranulomatosa e ulcerativa. A avaliação da susceptibilidade in vitro do C. pseudotuberculosis a antimicrobianos demonstrou que o agente era resistente à amicacina, kanamicina, neomicina e penicilina G, apresentando sensibilidade à ampicilina adicionada de subactam, amoxicilia com ácido clavulônico, cefalexina, cefalotina, cefotaxima, enrofloxacina, gentamicina e tetraciclina. A retirada cirúrgica das lesões e o tratamento com enrofloxacina resultaram na cura do animal. Lesões de pele observadas em casos de ptiose, carcinoma de células escamosas e na forma atípica da actinobacilose devem ser consideradas no diagnóstico diferencial da forma cutânea da infecção por C. pseudotuberculosis em bovinos. Os dados apresentados demonstram que a infecção pelo C. pseudotuberculosis deve ser considerada no diagnóstico diferencial das lesões de pele em bovinos no Brasil.
\end{abstract}

Palavras-chaves: dermatopatias, ruminantes, lesões piogranulomatosas

\begin{abstract}
We report a case of secondary skin lesionby infection with Corynebacterium pseudotuberculosis in bovine. Abscesses and multiple nodular lesions, ranging from $8 \times 10$ to $20 \times 25 \mathrm{~cm}$ in diameter, firm, sensitive to touch, and without mobility, some with ulcerated surface, surrounded by reddish halo and draining piosanguinolenta secretion, and other surfaces with alopecia, were identified in the skin of the animal 's thoracic area. Histopathology and isolation of the agent from fragments obtained after surgical removal of the lesions confirmed the cutaneous infection by C. pseudotuberculosis. Microscopic lesions were characterized by lumpy skin disease and ulcerative pyogranulomatous. Evaluation of in vitro susceptibility to antimicrobial demonstrated that the agent was resistant to amikacin, kanamycin, neomycin and penicillin $G$, and sensitive to ampicillin + subactam, amoxicilia with clavulonic acid, cephalexin, cephalothin, cefotaxime, enrofloxacin, gentamicin, and tetracycline. The surgical removal of the lesions, and treatment with enrofloxacin resulted in animal cure. Skin lesions observed in case of ptiose, squamous cell carcinoma and atypical form of Actinobacillosis should be considered in the differential diagnosis of cutaneous form of C. pseudotuberculosis infection in cattle. The data presented demonstrate that infection with C. pseudotuberculosis should be considered in the differential diagnosis of skin lesions in cattle in Brazil.
\end{abstract}

Keywords: skin diseases, ruminants, piogranulomatosas injuries

Recebido em 16 de abril de 2015

Aceito em 7 de julho de 2016

E-mail: glieresilmara@hotmail.com 


\section{INTRODUÇÃO}

As infecções por C. pseudotuberculosis são caracterizadas por processos piogranulomatosos crônicos em várias espécies de animais de produção (Motta et al., 2010), e geralmente um trauma tecidual precede o estabelecimento da infecção (Quinn et al., 2005). Esse agente é responsável por causar linfadenite caseosa em pequenos ruminantes, dermatite ulcerativa em bovinos, linfangite ulcerativa, abscessos nas regiões peitoral, axilar, abdominal ventral e inguinal de equinos (Hall et al., 2001) e granulomas em humanos (Peel et al., 1997).

Em bovinos, a infecção por $C$. pseudotuberculosis é prevalente em rebanhos leiteiros de Israel, podendo ocorrer de forma esporádica ou epidêmica (Yeruham et al., 1997; Motta et al., 2010), havendo relatos da ocorrência de formas clínicas cutâneas, mastítica, visceral (Yeruham et al., 1997; Yeruham et al., 2004), dermatite necrótica ulcerativa podal (Yeruham et al., 2004) e formas mistas. $\mathrm{Na}$ Índia, o agente foi identificado em nódulos linfáticos do mesentério de bezerro (Sood et al., 2012) e em lesões necróticas e ulcerativas da pele em bovinos no oeste dos Estados Unidos (Garry, 2008).

C. pseudotuberculosis raramente é mencionado como causa de doença nos bovinos (Garry, 2008). No Brasil, é comumente conhecido como a causa da linfadenite caseosa nos ovinos e caprinos, mas, segundo o conhecimento dos autores, não há relato da infecção em bovinos. $\mathrm{O}$ objetivo deste trabalho é relatar um caso de infecção cutânea por C. pseudotuberculosis em bovino na região semiárida do Brasil, caracterizando seus aspectos clínicos, epidemiológicos, patológicos e microbiológicos.

\section{CASO CLÍNICO}

A doença ocorreu em uma fêmea bovina, com seis anos de idade, proveniente do município de Emas, estado da Paraíba, que foi atendida no Hospital Veterinário da Universidade Federal de Campina Grande, em julho de 2013. Segundo o proprietário, o animal havia sido adquirido recentemente e há 11 dias apresentava lesão cutânea caudal à escápula, que inicialmente era pequena e drenava sangue e depois evoluiu para grandes massas com tratos fistulosos drenando secreção amarelada e fétida. $\mathrm{Na}$ fazenda, foi instituído tratamento com oxitetraciclina durante três dias, porém não houve êxito. A doença acometeu apenas um animal da propriedade.

No exame físico, observaram-se, na região torácica lateral direita e sobre a escápula, múltiplas lesões cutâneas nodulares, variando de $8 \times 10$ para $20 \times 25 \mathrm{~cm}$ de diâmetro, arredondadas, firmes, sensíveis ao toque e sem mobilidade, algumas com superfície ulcerada, irregular, circundada por halo avermelhado, e outras com superfície alopécica, com trato fistuloso central drenando secreção piossanguinolenta (Fig. 1). Observou-se que a temperatura era mais elevada na periferia da lesão do que no seu centro. Os linfonodos cervicais superficiais e subilíacos encontravam-se hipertrofiados.
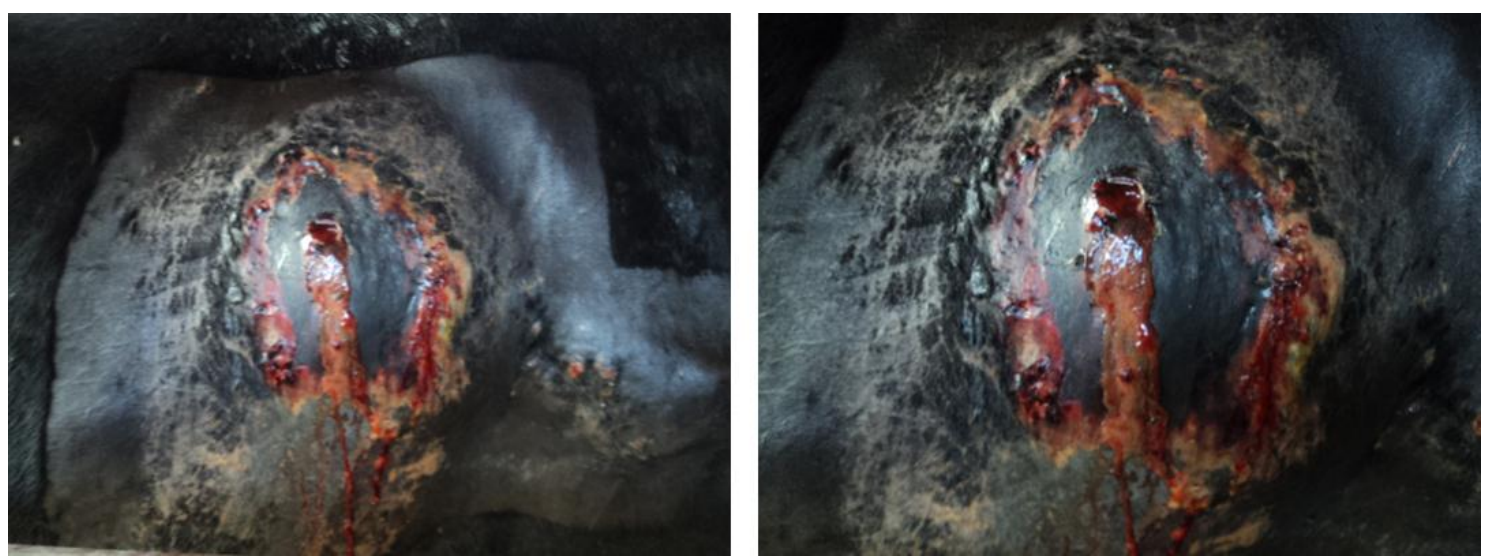

Figura 1. Bovino com lesão de pele piogranulomatosa causada por C. pseudotuberculosis, situada caudalmente à escápula no antímero direito. 
Após a avaliação clínica e considerando a gravidade das lesões, optou-se por realizar a remoção cirúrgica delas. O material obtido na cirurgia foi encaminhado ao Laboratório de Patologia Animal e ao Laboratório de Microbiologia da UFCG para realização de exame histopatológico e microbiológico, respectivamente. Macroscopicamente observouse que, na superfície de corte desses fragmentos de pele, havia na derme nódulos multifocais a coalescentes, medindo de 0,2 a $0,4 \mathrm{~cm}$ de diâmetro, amarelados, firmes, bem como múltiplas cavitações contendo material amarelo acinzentado e friável, ambos circundados por tecido esbranquiçado, liso e brilhante (Fig. 2). As lesões microscópicas caracterizaram-se por dermatite nodular piogranulomatosa e ulcerativa. $\mathrm{Na}$ derme superficial e profunda, observaram-se piogranulomas multifocais a coalescentes constituídos por necrose central de neutrófilos, circundada por macrófagos, macrófagos epitelioides, alguns linfócitos e eosinófilos e múltiplas células gigantes multinucleadas, às vezes delimitados por tecido conjuntivo fibroso. Adicionalmente, verificaram-se poucos granulomas conspícuos sem necrose central. Adjacentes a essas áreas, havia eosinófilos e, menos frequentemente, linfócitos e macrófagos dispersos em meio ao tecido conjuntivo, às vezes situados ao redor de vasos.
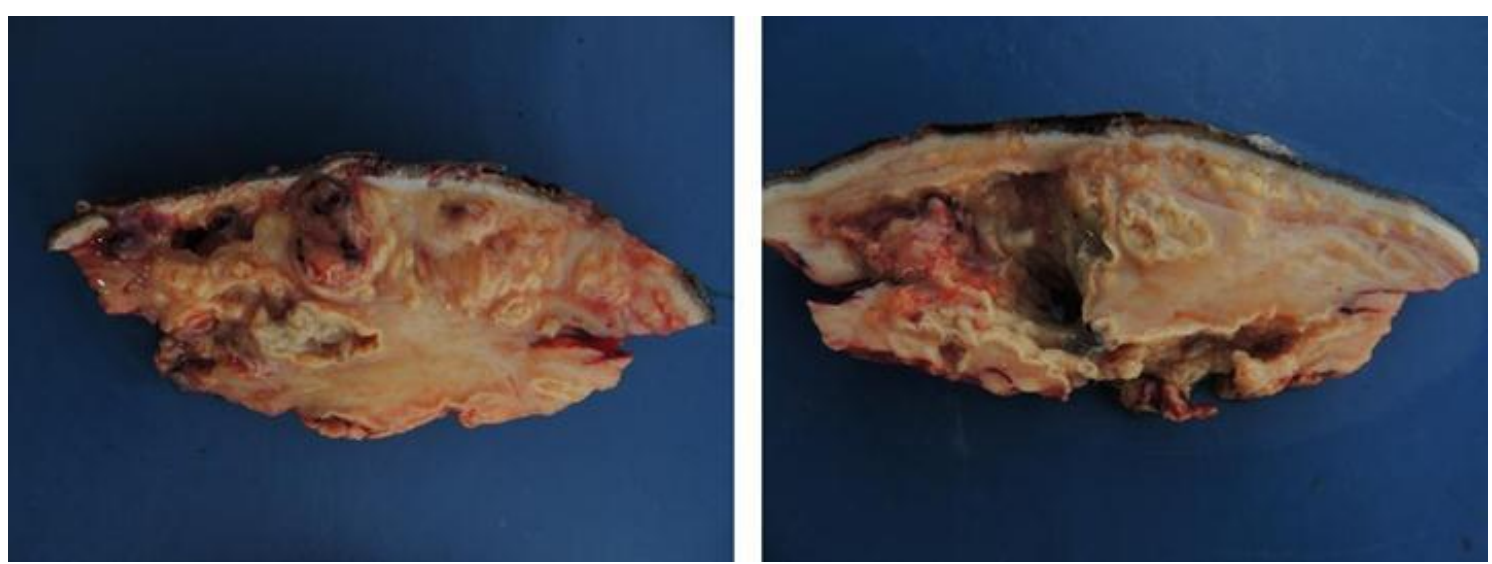

Figura 2. Fragmentos de lesão piogranulomatosa da pele de bovino causada por C. pseudotuberculosis, evidenciando a formação de nódulos amarelados multifocais e cavitações com conteúdo necrótico.

A semeadura do conteúdo purulento colhido das lesões piogranulomatosas foi realizada em placas de ágar-sangue enriquecido com sangue ovino $5 \%$, ágar MacConkey e caldo Brain Heart Infusion (BHI), incubadas em aerobiose a $37^{\circ} \mathrm{C}$. Após 48 horas, foi possível a visualização de colônias redondas apresentando forma seca, opaca e concêntrica de coloração esbranquiçada no meio ágar-sangue. Microscopicamente, visualizaram-se bactérias Gram-positivas na forma de bastonetes. Por meio da associação de provas bioquímicas, foi verificado que o agente demonstrou-se catalase e urease positivos, nitrato e esculina negativos, fermentador de maltose, sacarose, glicose e galactose, não fermentador de xilose e D-manitol, apresentando CAMP-teste reverso, sendo identificado conforme o Manual of Clinical Microbiology (Funke e Bernard, 1999) como C. pseudotuberculosis.
A avaliação da susceptibilidade in vitro do $C$. pseudotuberculosis a 12 diferentes antimicrobianos, realizada por meio do teste de disco-difusão pelo método de Kirby-Bauer em ágar Müller Hinton, demonstrou que o agente era resistente à amicacina, kanamicina, neomicina e penicilina $\mathrm{G}$ e sensível à ampicilina adicionada de subactam, amoxicilia com ácido clavulônico, cefalexina, cefalotina, cefotaxima, enrofloxacina, gentamicina e tetraciclina.

Após a exérese da lesão, foi instituído tratamento com antibiótico à base de enrofloxacina $10 \%$ $(5 \mathrm{mg} / \mathrm{kg}$, intramuscular, a cada 24 horas, durante 10 dias), anti-inflamatório não esteroidal, fenilbutazona $(4 \mathrm{mg} / \mathrm{kg}$, intravenoso, a cada 24 horas, durante três dias) e tratamento local de ferida cirúrgica com antisséptico (clorexidine degermante $2 \%$ ), açúcar e pomada fitoterápica à base de extrato hidroalcoólico de 
Plectranthusneochilus. Após 10 dias de tratamento (Fig. 3), o animal recebeu alta médica e foi encaminhado para a propriedade, onde o tratamento local da ferida teve continuidade até completa cicatrização.
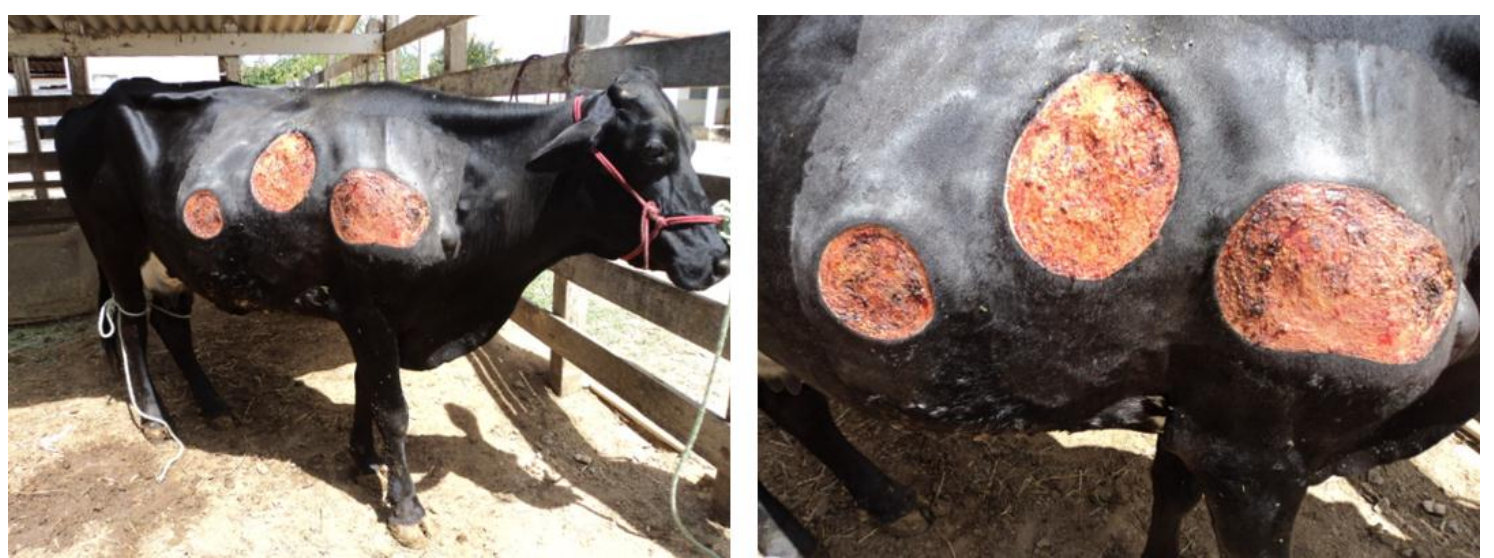

Figura3. Bovino com lesões em processo de cicatrização após 10 dias de exérese da lesão piogranulomatosa na pele causada por C. pseudotuberculosis.

\section{DISCUSSÃO}

O isolamento do agente das lesões confirmou tratar-se da forma cutânea da infecção pelo $C$. pseudotuberculosis em bovinos. As dimensões das lesões e a localização, assim como as características macroscópicas, de edema, ulceração central, drenagem de secreção e sensibilidade, estão de acordo com o descrito por Yeruham et al. (1997); Yeruham et al. (2004) em bovinos leiteiros de rebanhos israelenses. Esses mesmos autores observaram na microscopia presença de numerosos nódulos contendo pus cercados por células epitelioides e células gigantes multinucleadas.

O processo inflamatório, o edema local e a necrose que envolve a lesão são atribuídos a fatores de virulência do microrganismo, principalmente à ação da fosfolipase $\mathrm{D}$, uma exotoxina dermonecrótica e hemolítica, capaz de aumentar a permeabilidade vascular e contribuir para a disseminação do patógeno para linfonodos regionais (Motta et al., 2010).

Os dados apresentados demonstram que a forma cutânea da infecção pelo C. pseudotuberculosis deve ser considerada no diagnóstico diferencial das lesões de pele em bovinos, especialmente na região semiárida do Brasil, como lesões de ptiose, carcinoma de células escamosas e actinobacilose atípica. O diagnóstico definitivo dessa infecção deve ser realizado por meio da identificação microbiológica do agente e da histopatologia da lesão (Yeruham et al., 2004).

A cepa de C. pseudotuberculosis isolada respondeu negativamente ao teste bioquímico para redução do nitrato, corroborando o citado por Yeruham et al. (2004). De acordo com Quinn et al. (2005), o C. pseudotuberculosis possui dois biótipos denominados ovis e equi, definidos pela sua capacidade de produzir a enzima nitratoredutase, que permite a conversão do nitrato para nitrito em provas bioquímicas.

O biótipo ovis não possui capacidade de reduzir o nitrato, sendo este considerado negativo na prova bioquímica de redução do nitrato. $\mathrm{O}$ biótipo equi possui capacidade de reduzir o nitrato. Os bovinos podem ser infectados pelos dois biótipos (Motta et al., 2010).

Yeruham et al. (2004) explicam que provavelmente a disseminação da infecção por C. pseudotuberculosis em rebanhos bovinos leiteiros de Israel ocorre pela introdução de animais infectados em rebanhos livres da infecção. A transmissão pode ocorrer de forma mecânica por meio de moscas domésticas e outros artrópodes. Além disso, rebanhos de ovinos e caprinos infectados também podem servir como fontes de infecção.

No Brasil, a causa mais provável de a infecção ocorrer em bovinos é o contato com rebanhos de 
ovinos e caprinos com alta prevalência da infecção. O C. pseudotuberculosis é o agente etiológico da linfadenite caseosa, doença muito prevalente em caprinos e ovinos na região Nordeste, onde a prevalência de animais com sinais clínicos pode chegar a 50\% (Riet-Correa, 2007). Esse agente é capaz de permanecer viável no meio ambiente por longos períodos. A presença de numerosas plantas cactáceas, capazes de provocar ferimentos na pele dos animais, é considerada uma das causas da alta prevalência da infecção por essa bactéria em pequenos ruminantes no Nordeste. Sood et al. (2012) também consideram os rebanhos de caprinos e ovinos infectados como sendo fontes de infecção para os bovinos.

Embora C. pseudotuberculosis possa produzir biofilme, considerado eficiente na proteção contra vários antibióticos (Olson et al., 2002), o uso da terapia antimicrobiana após a exérese da lesão foi efetiva para o tratamento e controle desse agente no presente trabalho. Foram demonstradas sensibilidades in vitro e in vivo da bactéria à enrofloxacina, o que possibilita a indicação desse antibiótico no tratamento de infecções por C. pseudotuberculosis em bovinos.

\section{REFERÊNCIAS}

FUNKE， G.; BERNARD, K.A. Coryneform gram-positive rods In: MURRAY, P.R.; BARON, E.J.; PFALLER M.A. et al. Manual of clinical microbiology. 7.ed. Washington: American Society for Microbiology, 1999. p.319-345.

GARRY, F. Miscellaneous infectious diseases. In: REBHUN, W.C. (Ed.). Diseases of dairy cattle. St. Loius: Saunders Elsevier, 2008. p.606639.

HALL, K.; McCLUSKEY, B.J.; CUNNINGHAM, W. Corynebacterium pseudotuberculosis infections (pigeon fever) in horses in western Colorado: an epidemiological investigation. J. Equine Vet. Sci., v.21, p.284-286, 2001.
MOTTA, R.G.; CREMASCO, A.C.M.; RIBEIRO, M.G. Infecções por Corynebacterium pseudotuberculosis em animais de produção. Vet. Zootec., v.17, p.200-213, 2010.

OLSON, M.E.; CERI, H.; MORCK, D.W. et al. Biofilm bacteria formation and comparative susceptibility to antibiotics. Can. J. Vet. Res., v.66, p.86-92, 2002.

PEEL, M.M.; PALMER, G.G.; STACPOOLE, A.M.; KERR, T.G. Human lymphadenitis due to Corynebacterium pseudotuberculosis: report of ten cases from Australia and review. Clin. Infect. Dis., v.24, p.185-191, 1997.

QUINN, P.J.; MARKEY, B.K.; CARTER, M.E. et al. Microbiologia veterinária e doenças infecciosas. Porto Alegre: Artmed, 2005. p.6770 .

RIET-CORREA, F. Linfadenite caseosa. In: RIET-CORREA, F.; SCHILD, A.L.; LEMOS, R.A.A.; BORGES, J.R.J. Doenças de ruminantes e equinos. 3.ed. Santa Maria: Pallotti, 2007. p.347-351.

SOOD, N.K.; SANDHU, B.S.; GUPTA, K. et al. Mesenteric caseous lymphadenitis in a cow calf causedby Corynebacterium pseudotuberculosis: a case report. Vet. Med., v.57, p.371-375, 2012.

YERUHAM, I.; ELAD, D.; VAN-HAM, M. et al. Corynebacterium pseudotuberculosis infection in Israeli cattle: clinical and epidemiological studies. Vet. Rec., v.140, p.423427, 1997.

YERUHAM, I.; FRIEDMAN, S.; PERL, S. et al. A herd level analysis of a Corynebacterium pseudotuberculosis outbreak in a dairy cattle herd. Vet. Dermatol., v.15, p.315-320, 2004. 